\title{
Erratum zu: Zum Beispiel Kabeljau und Hering: Fischerei, Überfischung und Fischereimanagement im Nordatlantik
}

\section{Christopher Zimmermann und Cornelius Hammer}

\section{Erratum zu:}

G. Hempel, K. Bischof, W. Hagen (Hrsg.), Faszination Meeresforschung, https://doi.org/10.1007/978-3-662-49714-2

Aufgrund aktueller Entwicklungen ist es notwendig die Abbildungen 39.2, 39.3, 39.5 und deren Bildunterschriften zu aktualisieren. Außerdem wurde die folgende Literaturstelle im Kapitel ergänzt.

ICES (2019) ICES Stock Assessment Database. Copenhagen, Denmark. ICES. [01.11.2019]. http://standardgraphs.ices.dk

Die korrigierte Version der Titelei ist verfügbar unter:

https://doi.org/10.1007/978-3-662-49714-2

Die aktualisierte Version des Kapitels 39 kann hier abgerufen werden:

https://doi.org/10.1007/978-3-662-49714-2_39

Dr. Christopher Zimmermann ( $ه)$

Thünen-Institut für Ostseefischerei

Alter Hafen Süd 2, 18069 Rostock, Deutschland

E-Mail: christopher.zimmermann@ti.bund.de 